\title{
A qualidade educacional no Projeto de Educação em Tempo Integral no Estado do Amazonas'
}

\author{
Educational quality in the Full-Time Education Project in the Stade of \\ Amazonas
}

\section{Calidad educativa em el Proyecto de Educación de Tiempo Completo em el Estado de Amazonas}

\begin{abstract}
Angela Maria de Oliveira ${ }^{2}$
Universidade Federal do Amazonas, Instituto de Educação, Agricultura e Ambiente, Curso de Pedagogia, Professora Adjunta; Universidade Federal de Rondônia, Programa de Pós Graduação em Educação, Professora Colaboradora. https://orcid.org/0000-0003-1619-8958
\end{abstract}

Resumo: A temática de educação em tempo integral no Brasil remonta a segunda metade do século XX com a criação, por Anísio Teixeira em 1950, do Centro Educacional Carneiro Ribeiro, em Salvador, na Bahia. Nos anos de 1980 e 1990, grandes experiências vieram à lume por meio de pol'ticas estaduais, a exemplo dos CIEPs (1983, 1994). No século XXI, o tema voltou à baila por intermédio do Programa Mais Educação, em 2007, do Governo Federal No estado do Amazonas a educação em tempo integral surgiu em 2002, com a criação de um projeto piloto em duas escolas públicas estaduais. Essa experiência pedagógica tem por objetivo, elevar o padrão de qualidade da escola pública. Levando em consideração esse contexto e análise sobre o padrão de qualidade educacional como direito Constitucional, este artigo tem por objetivo demonstrar em que consiste o padrão de qualidade no Projeto de Educação em Tempo Integral, em voga, na rede estadual do Amazonas. Para alcançar tal objetivo, parte da seguinte questão: Qual a concepção de qualidade educacional presente no Projeto de Educação em Tempo Integral no estado do Amazonas. Para responder essa questão, utilizou-se, da pesquisa bibliográfica para a produção científica e da documentação oficial e se chegou à conclusão de que o projeto analisado adotou um conceito de qualidade que caminha na direção contrária à formação integral do sujeito quanto às dimensões intelectuais, físicas, sociais, ética e poĺticas, uma vez que adotou, como perspectiva formativa o slogan aprender a aprender, oriundo da perspectiva neoliberal.

Palavras-chave: Educação em tempo integral. Direito à educação. Educação com padrão de qualidade.

Abstract: The theme of full-time education in Brazil goes back to the second half of the 20th century with the creation, by Anisio Teixeira in 1950, of the Centro Educacional Carneiro Ribeiro, in Salvador, Bahia.

Parte da tese de doutorado defendida na Faculdade de Educação da Unicamp em 2019 cujo título: "0 Projeto de Educação em Tempo Integral no estado do Amazonas e o direito à educação" analisou os indicadores de acesso, permanência e qualidade da educação em tempo integral no Amazonas.

2 Doutora em Educação pela Universidade Estadual de Campinas; Mestre em Educação pela Universidade Federal de Rondônia. 
In the 1980s and 1990s, great experiences came to light through state policies, like the CIEPS - Centros Integrados de Educação Pública (1983, 1994). In the 21st century, the theme came up again through the Mais Educação Program, in 2007, by the Federal Government. In the state of Amazonas, full-time education emerged in 2002, with the creation of a pilot project in two public schools. These pedagogical experiences had, and aim to, raise the quality standard of the public school. Considering this context and analysis of the educational quality standard as a Constitutional right, this article aims to demonstrate what the quality standard consists of in the Full-Time Education Project, in vogue, in the public school system in Amazonas. To achieve this goal, it starts from the following question: What is the concept of educational quality present in the Full-Time Education Project in the state of Amazonas. To answer this question, bibliographic research for scientific production and official documentation was used and the conclusion was reached that the analyzed project adopted a concept of quality that goes in the opposite direction to the integral formation of the subject regarding intellectual dimensions, physical, social, ethical and political, since it adopted, as a formative perspective, the slogan "learn to learn", coming from the neoliberal perspective.

Keywords: Full-time education. Right to education. Education with quality standards.

Resumen: El tema de la educación a tiempo complete en Brasil se remonta a la segunda midad del siglo XX con la creación, por Anísio Teixeira en 1950, del Centro Educacional Carneiro Ribeiro, en Salvador, Bahía. En las décadas de 1980 y 1990, grandes experiencias saloeron a la luz a atraves de politicas estatales, como los CIEP $(1983,1994)$. En el siglo XXI, el tema, el tema volvió a surgir a través del Programa Mais Educacion, en 2007, del Gobierno Federal. En el estado de Amazonas, la educación a tiempo complete surgió en 2002, com la creación de un Proyecto piloto en dos escuelas públicas estatales. Estas experiencias pedagógicas tivieron, y tienen como objetivo, elevar el estándar de calidad de la escuela pública. Teniendo en cuenta este context y análisis del estándar de calidade educative como derecho constitucional, este artículo tiene como objetivo demonstrar en qué consiste el estándar de calidade en el Proyecto de Educacioón a Tiempo Completo, en boga em la red del estado do Amazonas. Para lograr este objetivo, se parte de la siguiente pregunta: ¿̇Cuál es el concepto de calidad educativa presente en el Proyecto de Educación a Tiempo Completo en el estado de Amazonas? Para responder a esta pregunta se utilizó la investigación bibliográfica para la producción científica y la documentación oficial, y se llegó a la conclusión de que el proyecto analizado adoptó un concepto de calidad que va en sentido contrario a la formación integral del sujeto en las dimensiones intelectuales, físico, social, ético y político, ya que adoptó, como perspectiva formativa, el lema aprender a aprender, proveniente de la perspectiva neoliberal

Palabras clave: Educación a tiempo completo. Derecho a la educación. Educación con estándares de calidad. 


\section{INTRODUÇÃO}

Este trabalho é parte da tese de doutorado defendida na Unicamp em 2019 cujo título "0 Projeto de Educação em Tempo Integral no Estado do Amazonas e o Direito à Educação" procurou analisar o Projeto de Educação em Tempo Integral no estado do Amazonas, tendo em vista o direito à educação de acordo com os princípios constitucionais de acesso, permanência e qualidade.

Neste artigo trataremos exclusivamente da dimensão qualidade, cujo objetivo é demonstrar em que consiste o padrão de qualidade no Projeto de Educação em Tempo Integral, em voga, na rede estadual do Amazonas.

A oferta de Educação Básica de qualidade foi normatizada pela Constituição Federal de 1988 (BRASIL, 1988), ratificado pela Lei de Diretrizes e Bases da Educação - LDB 9394/96 (BRASIL, 1996), e, ainda, validada pelo Plano Nacional de Educação PNE 2014/2024 (BRASIL, 2014). 0 Plano Estadual de Educação do Amazonas, PEE-AM 2015-2025, estabeleceu a seguinte meta sobre a qualidade da educação no estado:

Fomentar a qualidade da Educação Básica em todas as etapas e modalidades, com melhoria do fluxo escolar e da aprendizagem, de modo a atingir as seguintes médias estaduais para o IDEB: 5,4 nos Anos Iniciais do Ensino Fundamental; 4,8 nos anos finais do ensino fundamental; 4,2 no ensino médio. (AMAZONAS, 2015, p. 64).

Efetivar uma educação de qualidade apresenta-se como um grande desafio para as políticas públicas e para o conjunto dos agentes que atuam no campo da educação, sobretudo, nas escolas públicas. Num contexto de Estado Neoliberal, a qualidade da educação é vista a partir de conceitos meritocráticos fundamentados nas avaliações em larga escala.

Dourado, Oliveira e Santos (2007) defendem que a qualidade da educação pode ser analisada a partir de fatores extraescolares e intraescolares. Àqueles referem-se à situação socioeconômica dos estudantes que tem influência direta na vida escolar dos mesmos. Quanto aos fatores intraescolares, existem um conjunto de aspectos que interferem na qualidade da educação, dentre os quais: a gestão escolar, a estrutura física e pedagógica da unidade escolar, o curriculum, as avalições externas, materializadas pelo ĺndice de Desenvolvimento da Educação (IDEB). Soma-se a isso, a formação e carreira docente e suas efetivas condições de trabalho. 
A partir da Reforma do Estado ocorrida na década de 90 do século XX ICARDOSO, 1999) a administração escolar traz, em seu bojo histórico, a teoria geral da administração, cujas principais características eram a centralização e a hierarquização das atividades administrativas. Tais características foram incorporadas pela gestão das escolas, cuja atuação do diretor comparava-se ao de um gerente de empresas capitalistas (PAR0, 2015), a partir de uma administração respaldada pela "Qualidade Total”, em detrimento da qualidade social da educação. Nessa concepção, a gestão escolar passou a ser organizada, principalmente, pelo controle sistêmico do trabalho, dos tempos e espaços escolares.

De acordo com Menezes (2009, p. 94, grifo do autor),

0 Estado do Amazonas começa a entrar timidamente no projeto neoliberal da gestão pela Qualidade Total no ano de 1997 quando na gestão do secretário José Melo de Oliveira foi adquirido um projeto de implantação da Gestão pela Qualidade Total junto à Fundação Christiano Ottoni (FCO) para 19 escolas estaduais do município de Manaus.

A adesão do estado do Amazonas ao projeto da "Qualidade Total", implantado, gradativamente, em várias escolas da rede estadual do Amazonas, tinha como objetivo a efetivação de uma educação de qualidade, voltada para atender aos interesses econômicos. Posteriormente, tal projeto recebeu nova denominação "Programa de Excelência da Gestão Escolar do Amazonas" (PEGEAM). A alteração na denominação do projeto em nada mudou a realidade das escolas públicas do estado, uma vez que, segundo Menezes (2009), a qualidade da educação, amparada em dados estatísticos, continuava sem melhorias.

A continuidade ao PEGEAM subsidiou o governo do estado a criar, em 2012, outro programa: "ISO nas escolas", a partir da Implantação e Certificação do Sistema de Gestão da Qualidade ISO 9001: 2008. 0 referido programa tinha como objetivo:

A implantação e certificação da escola no sistema de gestão da qualidade ISO 9001: 2008 visa a melhoria dos serviços prestados, o aumento da produtividade e eficiência das áreas administrativas e técnicas, aproveitamento de recursos, otimização do trâmite interno, implantação de boas práticas administrativas com o intuito de manter os clientes internos e externos satisfeitos. (AMAZONAS, 2012, p. 1).

A partir do exposto, podemos inferir que as escolas públicas da rede estadual do Amazonas continuam seguindo as orientações impostas pelas reformas educacionais de cunho neoliberal, cuja qualidade da educação é vista a partir de princípios meritocráticos, sem preocupação com a formação humana em suas múltiplas vertentes. 
Neste trabalho, procuramos analisar em que consiste o padrão de qualidade no Projeto de Educação em Tempo Integral, em voga, na rede estadual do Amazonas.

No primeiro momento apresentamos o percurso metodológico da pesquisado a partir de uma revisão bibliográfica e documental. No segundo item, apresentamos como essa modalidade de ensino foi se consolidando na rede pública estadual do Amazonas. No terceiro e último item, tratamos exclusivamente da qualidade da educação no Projeto de Educação em Tempo Integral.

\section{O PERCURSO METODOLÓGIICO DA PESQUISA}

Como já informado na introdução, este trabalho é parte da pesquisa de doutoramento, defendida na Unicamp em 2019. Para a construção da mesma, adotamos a revisão bibliográfica e a análise documental como procedimentos metodológicos, explorados a partir de uma abordagem qualitativa (ALVES-MAZZOTTI; GEWANDSZAJER, 2002).

A revisão bibliográfica foi realizada no sítio Scientific Eletronic Library Online SciELO e no Banco de Teses e Dissertações da CAPES no período de 14 de dezembro de 2017 a 02 de janeiro de $2018{ }^{3}$

No sítio do Scientific Eletronic Library Online - SciELO, utilizando os descritores: "Educação de Tempo Integral" e "Educação em Tempo Integral" foram encontrados os seguintes trabalhos: "Para onde caminham os Cieps? Uma análise após 15 anos" (CAVALIERE; COELHO, 2003): “Conhecimentos Praticados na Escola de Tempo Integral (COELHO; MAURÍCIO, 2016); Escola pública de tempo integral no Brasil: filantropia ou política de Estado? (CAVALIERE, 2014); "Educação integral: uma nova identidade para a escola brasileira?" (CAVALIERE, 2002). Tais artigos e outras obras (MACIEL, 2013, 2016); (PARO, 2015), que tratam sobre o assunto, nos deram embasamento teórico para compreensão geral sobre o objeto de estudo.

Sobre a temática tempo escolar e qualidade na educação, utilizamos os descritores: "Qualidade na Educação" e "Tempo escolar na educação integral" e encontramos os seguintes trabalhos: "Tempo de escola e qualidade na educação pública" (CAVALIERE, 2007); "Escolas de tempo integral versus alunos em tempo integral" (CAVALIERE, 2009), que trataram sobre a temática do tempo escolar. Sobre qualidade na educação, encontramos e estudamos o artigo: "Qualidade da Educação: conceitos e definições” (DOURADO; OLIVEIRA; SANTOS, 2007).

Período de coleta para a tese de doutoramento. 
Com o descritor "Educação em Tempo Integral no Amazonas" foi encontrado apenas um artigo "Educação e Diversidade: Interfaces e Desafios na Escola de Tempo Integral" (COLARES; SOUZA, 2015).

No Catálogo de Teses e Dissertações encontramos os seguintes trabalhos com o mesmo descritor: "Modelos de gestão escolar no Estado do Amazonas: entre o dito e o feito (MENEZES, 2009); “0 Ensino Médio nas escolas de tempo integral” (FERREIRA, 2012) e "Programa escola integral no Amazonas: um estudo sobre a organização do tempo em uma escola de Manaus" (CARDOSO, 2016); "0 Sistema Público de Educação de Tempo Integral em Manaus e as possibilidades da Educação Integral Politécnica" (SILVA, 2017).

Encontramos também no google acadêmico a obra publicada pelo Fundo de Emergência Internacional das Nações Unidas para a Infância (UNICEF) em 2013, cujo título: "Percursos da Educação Integral: em busca da qualidade e da equidade" aborda sobre os vários programas de Educação em Tempo Integral no Brasil, dentre os quais, do estado do Amazonas.

Os artigos, teses e dissertações analisadas, favoreceram a compreensão e o aprofundamento sobre a temática da Educação de Tempo Integral no estado Amazonas, mostrando-nos o início dessa modalidade de ensino na rede estadual e nos permitiram o acesso a outras fontes bibliográficas.

$\mathrm{Na}$ análise documental, delimitamos como foco de investigação os determinantes legais referentes ao Projeto de Educação em Tempo Integral no estado do Amazonas, a saber: Constituição do Estado do Amazonas, quais sejam: Planos Estaduais de Educação (2008 e 2015); Relatório da Conferência Estadual de Educação; Resoluções do Conselho Estadual de Educação do estado do Amazonas (Resolução ११/2008 (CONSELHO ESTADUAL DE EDUCAÇÃO DO AMAZONAS, 2008) e Resolução 17/2011 (CONSELHO ESTADUAL DE EDUCAÇÃO DO AMAZONAS, 2011); Projetos de Educação em Tempo Integral elaborado pela Secretaria de Educação - Seduc: (2008 e 2011).

Todo esse percurso metodológico, nos permitiram melhor compreensão e análise do nosso objeto de estudo.

\section{A EDUCAÇÃO EM TEMPO INTEGRAL: ASPECTOS INICIAIS NA REDE ESTADUAL DO AMAZONAS}

A temática sobre Educação em Tempo Integral no Brasil vem sendo debatida em vários períodos da história da educação brasileira. De acordo com Cavaliere (2010, p. 249), "No 
Brasil, a compreensão da maneira pela qual a concepção de educação integral se desenvolve passa obrigatoriamente pelo estudo do pensamento educacional das décadas de 20 e 30 do século XX."

Mesmo sem utilizar a expressão "educação integral", a ideia de Educação em Tempo Integral a partir da ampliação do tempo escolar e das novas funções da escola foi defendida e efetivada pelo educador e político Anísio Teixeira (1900-1971), sendo esse um dos pilares de seu pensamento educacional, conforme nos mostra Cavaliere (2010, p. 250):

\begin{abstract}
As bases de uma concepção de educação escolar que alcançasse áreas mais amplas da cultura, da socialização primária, da preparação para o trabalho e para a cidadania estavam presentes desde os primórdios do percurso de Anísio Teixeira como pensador e político. Essa concepção foi sendo desenvolvida e aperfeiçoada por toda a sua obra e envolveu diversos elementos, entre esses a sua permanente defesa do aumento da jornada escolar discente nos diferentes niveis de ensino.
\end{abstract}

0 educador, inspirado nas experiências vivenciadas durante seus estudos nos Estados Unidos, ${ }^{4}$ em sua volta para o Brasil, propôs um projeto para reconstrução da educação brasileira a partir de uma concepção de educação com jornada ampliada; com caráter formativo mais amplo e efetivamente democrático; uma educação de qualidade em oposição ao processo de expansão da escolarização em massa da população, presente à época (CAVALIERE, 2010). Foi nessa direção que o educador implantou, em 1950, o Centro Educacional Carneiro Ribeiro, em Salvador, na Bahia.

Inspirado nas ideias de Anísio Teixeira, no que concerne à defesa de uma escola pública em tempo integral, na década de 1980 o então vice-governador e antropólogo Darcy Ribeiro (1922-1997) implantou o Programa Especial de Educação-PEE no estado do Rio de Janeiro, cujo objetivo era romper com o autoritarismo presente na escola pública, comprometendo-se com os ideais democráticos criando os Centros Integrados de Educação Pública - CIEPs (CAVALIERE; COELHO, 2003).

Essas foram duas das principais políticas de educação em tempo integral no Brasil, que serviram de inspiração para diferentes projetos e programas, posteriormente efetivados no nos diversos entes federados.

No estado do Amazonas, a discussão sobre a Educação em Tempo Integral, parte da Constituição Estadual promulgada em 05 de outubro de 1989, cujo art. 199 tratou sobre

\footnotetext{
4 Como diretor da Instrução Pública do Estado da Bahia, Anísio Teixeira teve contato com as obras de John Dewey e W. H. Kilpatrick, as quais marcaram fortemente sua formação e the deram as bases teórico-filosóficas para a construção de um projeto de reforma para educação brasileira (CAVALIERE, 2010, p. 250).
} 
os princípios da educação, determinando no inciso I a "implantação progressiva do turno de oito horas diárias no ensino pré-escolar, alfabetização e de primeiro grau." (AMAZONAS, 1989).

Mesmo com essa determinação constitucional, somente em 2002, que o estado do Amazonas deu os primeiros passos em direção à efetivação do cumprimento desse princípio com a criação de um projeto piloto, em duas unidades escolares, pertencentes à rede estadual de educação.

Segundo Cardoso (2016), Ferreira (2012), Maciel et al. (2013, 2016), essas duas escolas viviam um período de graves problemas como o alto índice de abandono escolar, principalmente pela necessidade de entrada dos jovens no mercado de trabalho; problemas relacionados à adolescência, como o uso indevido de drogas e gravidez precoce; e, ainda, a desmotivação e a falta de entusiasmo pelo estudo, levando a um alto índice de reprovação. Diante dessa realidade, a ampliação da jornada escolar foi proposta como uma estratégia para os alunos do ensino médio, no combate à redução do índice de vulnerabilidade social, como se observa no documento publicado em 2013, pelo Fundo das Nações Unidas para a Infância (UNICEF).

\footnotetext{
A saida encontrada pela Escola Marcantonio Vilaça foi readequar a matriz curricular e envolver ativamente os jovens em projetos de iniciação científica, nos quais a curiosidade de descobrir o mundo é constantemente aguçada. Para tanto, investiu-se na reestruturação de locais dentro da escola que pudessem oferecer maiores oportunidades pedagógicas aos alunos. Os laboratórios e espaços ociosos ganharam vida e proporcionaram aos alunos uma nova relação com esse ambiente. (UNICEF, 2013).
}

De acordo com Cavaliere (2007), a experiência do Amazonas, ao iniciar o atendimento de Educação em Tempo Integral com o Ensino Médio, foi um caso raro no país e que motivou a criação de outras Políticas de Educação em Tempo Integral em vários entes da federação.

Em 2005, o governo do estado do Amazonas, propôs a mudança de algumas escolas de tempo parcial para tempo integral, adaptando os prédios escolares para atender esse modelo de ensino, criando as Escolas de Educação em Tempo Integral (EETI) (MACIEL, 2016; SILVA, 2017).

Compreendemos que tal experiência na rede estadual do Amazonas promoveu um modelo de educação até então inexistente no estado, despertando o interesse maior das famílias de estudantes que almejavam, e ainda almejam para seus filhos escolas de qualidade, mesmo sem a clareza quanto ao conceito de qualidade. 
Vale ressaltar que tais experiências antecederam a Portaria Ministerial $n^{\circ}-17$, de 24 de abril de 2007, que institui o Programa Mais Educação, fomentando a ampliação da jornada em escolas nos entes federados (BRASIL, 2007).

A partir dessas experiências, a temática da Educação em Tempo Integral passou a fazer parte da agenda de governo do estado, sendo apresentada nas propostas governamentais e discutida em conferências e nos planos estaduais de educação.

Em 2008, atendendo às determinações do Plano Nacional de Educação - PEE 20012011, o estado do Amazonas elaborou seu primeiro Plano Estadual de Educação - PEE/AM 2008, estabelecendo diretrizes e metas para a educação do estado. De acordo com o plano, uma das diretrizes foi: "Implementação gradativa do tempo integral na escola, objetivando a melhoria do processo de aprendizagem dos estudantes e, por conseguinte, dos indicadores educacionais do Estado." (AMAZONAS, 2008b, p. 26). A meta 16 previa:

\footnotetext{
Ampliar, progressivamente a jornada escolar visando expandir a escola de tempo integral, que abranja um período de pelo menos 07 (sete) horas diárias, com previsão de professores, equipe multidisciplinar e funcionários em número suficiente durante a vigência deste Plano. (AMAZONAS, 2008b, p. 28).
}

De acordo com o texto do plano, vislumbramos uma preocupação do estado em promover a educação em tempo integral para os estudantes do ensino fundamental e ensino médio, enfatizando que o direito a essas etapas de ensino não deveria figurarse apenas em estatísticas de matrícula, mas ser traduzido no direito indissociável entre acesso, permanência e qualidade do ensino tendo como desafio maior a universalização da Educação Básica com qualidade e em condições necessárias para permanência do estudante no contexto escolar (AMAZONAS, 2008b).

Utilizando o discurso de educação de qualidade, o Projeto de Educação em Tempo Integral no estado do Amazonas, durante o período de 2002 a 2008, foi se concretizando na rede estadual.

Em 20 de outubro de 2008, o Conselho Estadual de Educação publicou a Resolução n 112/2008 (CEE/AM, 2008) aprovando o Projeto das Escolas de Tempo Integral por 02 anos (art. $1^{\circ}$ ), autorizando o funcionamento de 8 (oito) escolas que já funcionavam com jornada ampliada desde 2002. De acordo com Ferreira (2012), desde esse período não foram construídas escolas específicas para o atendimento em tempo integral, apenas foram sendo adaptadas as EETls.

Tal projeto justificou-se tendo como parâmetro os resultados não satisfatórios das avaliações externas que mensuram a aprendizagem dos estudantes. De acordo com a 
justificativa do projeto, mesmo com as várias políticas de combate à reprovação, ao abandono escolar e à distorção idade-ano, ainda não tinha sido alcançado, em nível de estado, a "educação de qualidade" tão almejada. Foi nessa direção que a Secretaria de Estado de Educação e Qualidade do Ensino percebeu a necessidade de adotar outras possibilidades pedagógicas para a organização do ensino, principalmente em relação ao tempo e espaço de aprendizagem.

0 referido Projeto estabeleceu como objetivo geral:

\begin{abstract}
Oferecer aos educandos uma formação em tempo integral capaz de construir competências e habilidades de acordo com áreas de conhecimento e saberes necessários à vida. Desenvolvendo, assim, a ascensão social dos estudantes de baixa renda. Promover a permanência do educando, o convivio humano, o aproveitamento escolar, o bem-estar das crianças, dos adolescentes e jovens. (AMAZONAS, 2008a, p. 38).
\end{abstract}

Apostaram na ampliação do tempo escolar como estratégia, não somente em relação à quantidade de horas, mas, principalmente, visando melhorias no processo educativo. Um tempo escolar que envolveria tempo curricular, relação educador-educando-comunidade, bem como a construção e socialização do conhecimento. 0 Projeto estava assentado no tripé de desenvolvimento das habilidades cognitivas, social e emocional. Deveria ultrapassar o currículo tradicional de transmissão de conteúdo e focar na inter-relação entre as disciplinas e a realidade do estudante (AMAZONAS, 2008a).

0 projeto em questão

visava à extensão da jornada escolar para contribuir, na prática, um ganho na qualidade, bem-estar dos estudantes e o desenvolvimento pleno do cidadão, partindo de competências e habilidades, objetivando a interação do educando na sociedade, colaborando para a reconstrução de um mundo socialmente justo e promovendo a ascensão social dos estudantes de baixa renda. (AMAZONAS, 2008a, p. 38, grifo nosso).

De acordo com Colares (2015), o Projeto de Educação em Tempo Integral retomou as diretrizes adotadas na Conferência Mundial de Educação para Todos (1990), realizada em Jomtien, na Tailândia, com orientações das agências multilaterais como o Fundo Monetário Internacional (FMl) e o Banco Mundial, para o desenvolvimento pleno do cidadão. Para essas instituições, a educação deveria se adequar cada vez mais à era do mercado de modo a formar profissionais capazes de adaptar-se às contradições desse sistema. Nessa direção, 
o projeto em questão, ao adotar essas diretrizes, se propôs a efetivação de uma educação cada vez mais instrumental e menos politécnica. ${ }^{5}$

Com a Resolução $n^{\circ} 112 / 2008$, a rede de educação do estado do Amazonas caminhava para a ampliação das escolas de tempo integral por meio de um projeto arquitetônico padronizado para a construção dos Centros de Educação de Tempo Integral CETls, sendo, o primeiro, inaugurado em 2010 , com estruturara física e pedagógica planejadas para o funcionamento condizente ao que se propunha o projeto pedagógico das escolas de tempo integral.

De acordo com Colares e Souza (2015, p. 258),

Os Cetis são considerados centros de excelência por agregarem ambientes adequados e seguros aos alunos, oferecendo atividades em espaços como piscina semiolímpica, academia, sala de dança, sala de música, ginásio coberto, entre outros. [...] Os Cetis apresentam uma característica padrão de espaços e organização do trabalho pedagógico a fim de possibilitar o desenvolvimento de atividades intelectuais, fisicas e artísticas. A estrutura física comporta um projeto arquitetônico que envolve três pavimentos distribuídos em 96 dependências e com acessibilidade para portadores de necessidades especiais.

Maciel et al. (2013, p. 183) corrobora afirmando que: "Os CETls têm uma estrutura padronizada, visando atender tanto ao Ensino Médio, como ao Fundamental. Os CETls hoje são o modelo de estrutura educacional, em termos de educação de tempo integral, no estado do Amazonas."

Não negamos que os CETls contribuíram para a efetivação do Projeto de Educação em Tempo Integral, contudo, precisamos entender qual o projeto societário presente nessa proposta; a qual sociedade se propunha a atender e qual concepção de homem se propôs a formar. De acordo com Ferreira (2012, p. 66), os projetos dos CETls "Ajudaram a dar visibilidade ao projeto das escolas de tempo integral, tornando-o bandeira de campanha, produzindo efeitos favoráveis ao grupo político que se utilizou de uma retórica de convencimento por votos em áreas consideradas de "maior" vulnerabilidade social."

Observamos que as políticas educacionais, mais que atender às necessidades da população, servem como moeda de troca no processo eleitoral, nos levando a perceber que a implantação do Sistema de Educação de Tempo Integral no estado do Amazonas iniciou-se

A politecnia é um termo conferido a Marx, cujo propósito é uma formação que concebe o "desenvolvimento integral das faculdades humanas, tratando equilibradamente racionalidade, habilidade, sensibilidade e sociabilidade." (MACIEL et al., 2013). 
como uma política de governo, visando a interesses políticos partidários, em detrimento de uma política de Estado de caráter universal.

Maciel et al. (2013, p. 93) afirma que o Projeto de Educação em Tempo Integral do Amazonas "tem proporcionado condições mais adequadas de estudo, mas, ainda, apresentam falhas, que se constituem em verdadeiros desafios à implementação da educação integral", principalmente pelo viés mercadológico adotado, uma vez que, essa dinâmica, imposta pelas agências multilaterais continua prevalecendo, o que dificulta a efetivação de um processo educacional que tenha como foco principal a formação politécnica do estudante, com a vistas à construção de uma sociedade democrática.

Em 15 de março de 2011, o Conselho Estadual de Educação publicou a Resolução n. 17/2011 aprovando um "novo"6 Projeto de Educação em Tempo Integral, cujo título era: “Proposta Pedagógica das Escolas da Rede Estadual de Ensino de Educação em Tempo Integral".

A proposta justificava a necessidade da ampliação da jornada escolar, tendo em vista principalmente, a não universalização do Ensino Fundamental e o resultado insatisfatório nas avaliações externas na educação local, como também constava no projeto anterior. Assim, justificou-se a implantação do Projeto de Educação em Tempo Integral:

\begin{abstract}
0 avanço da cobertura quase universal do ensino público da Educação Básica do Brasil, segundo dados do Plano Nacional de Educação que demanda atualmente em $97 \%$ das crianças entre sete a catorze anos na sala de aula, ainda não tem sido satisfatório à aprendizagem. As avaliações que medem a aprendizagem não têm sido relevantes. Os resultados da avaliação do desempenho escolar realizados pelo Instituto Nacional de Estudos e Pesquisas Educacionais - INEP, com o Sistema de Avaliação da Educação Básica - Prova Brasil e SAEB e pela Organização para a Cooperação e Desenvolvimento Econômico - OCDE, que aplicou o Programa da Avaliação Internacional de Estudantes - PISA, demonstram que, apesar do avanço da matrícula, os estudantes da Educação Básica não alcançaram em qualquer das unidades federativas, médias satisfatórias nas avaliações de leitura e matemática. (AMAZONAS, 2011, p. 66).
\end{abstract}

Observamos que a justificativa para a implantação do projeto deu-se em torno dos resultados insatisfatórios nas avaliações externas e não como um direito constitucionalmente garantido pelo Estado como um direito público subjetivo (DUARTE, 2004).

0 Projeto de 2011 teve como objetivo geral: "Implementar e garantir, nas Escolas Estaduais de Educação em Tempo Integral da rede pública do estado do Amazonas, a melhoria

6 Utilizamos o termo "novo", pois, como veremos no decorrer do texto, este "novo" projeto teve poucas alterações em relação ao de 2008. 
do processo ensino aprendizagem elevando a 100\% o índice de aprovação e erradicando a evasão escolar." (AMAZONAS, 2011, p. 11),

Tomando como ponto de partida o objetivo geral da proposta que recomendou unicamente à "elevação a 100\% o índice de aprovação bem como a erradicação da evasão escolar", ficou evidente que o projeto foi efetivado para atender às exigências das avaliações externas e elevar o Índice de Desenvolvimento da Educação Básica - (IDEB) do estado de acordo com as orientações do Banco Mundial, conforme aponta o documento "Prioridades y Estrategias para la Educación" (1995), construído a partir das conclusões da Conferência Mundial de Educação para Todos (1990) determinavam que: "Las prioridades educacionales deben establecerse teniendo en cuenta los resultados, utilizando análisis económicos, estableciendo normas y midiendo los resultados a través de la evaluación del aprendizaje." (BANCO MUNDIAL, 1995, p. 30).

0 projeto de 2011 continuou com a mesma vertente ideológica do projeto de 2008 , atendendo às exigências impostas pelos organismos multilaterais de preparar o estudante para o mercado de trabalho; foi aprovado como política de governo e não como política social, de caráter universal, capaz de possibilitar a formação das múltiplas potencialidades educativas dos estudantes, contribuindo para sua autonomia e para a efetivação de uma sociedade democrática.

0 Plano Estadual de Educação, PEE 2015-2025, seguindo a mesma linha do PNE 2014-2024, estabeleceu como meta 06: "Implantar e implementar gradativamente educação em tempo integral em, no mínimo, $50 \%$ das escolas públicas, de forma a atender, pelo menos, $50 \%$ dos(as) estudantes da educação básica." (AMAZONAS, 2015, p. 54).

De acordo com o PPE/AM 2015-2025, para que o estado do Amazonas cumprisse a meta estabelecida seria necessário que, no mínimo, 166 escolas passassem a funcionar em tempo integral, ou que fossem construídas mais escolas. Para isso, o estado organizou a ampliação da jornada escolar nas diversas redes públicas de ensino utilizando-se quando possível de outros espaços físicos além dos existentes nas redes públicas de ensino (AMAZONAS, 2015).

A utilização de outros espaços, além da escola, para o atendimento da ampliação da jornada escolar é uma prática defendida por Cavaliere (2009), quando afirma que a escola pode buscar parcerias com outras instituições para esse atendimento, desde que as ações pedagógicas sejam planejadas e acompanhadas pela instituição escolar, conforme consta em seu Projeto Político Pedagógico. A autora afirma que a utilização desses outros espaços não pode representar um caráter minimalista da escola pública, com poucas horas diárias, poucos espaços e poucos profissionais, mas deve estar fundamentada num Projeto Político Pedagógico que caracterize o espaço escolar como um local de socialização e difusão da cultura. 
Para o cumprimento da meta 06 do PEE/AM, mais do que a garantia da ampliação do tempo escolar por meio de construção ou adequação de escolas, faz-se necessário efetivar o debate sobre a qualidade pedagógica desse tempo escolar. Um tempo que possibilite a educação integral dos estudantes, uma formação que reconheça a pessoa como um conjunto de dimensões formativas de todas suas potencialidades em relação aos aspectos cognitivo, físico, afetivo, social, ético e moral.

\section{A QUALIDADE DA EDUCAÇÃO NO PROJETO DE EDUCAÇÃO EM TEMPO INTEGRAL}

0 direito à educação, consubstanciado com a Constituição de 1988, traduziu-se como um direito inalienável ao homem com padrão de qualidade educacional, mesmo que o conceito de qualidade seja compreendido a partir de diferentes concepções.

0 Projeto em questão utilizou-se de um discurso da necessidade da efetivação de um ensino de qualidade, conforme nos mostra o documento:

\footnotetext{
0 Ensino Fundamental e Ensino Médio visando à melhoria da qualidade do ensino, por ser mobilizadores de uma ação pedagógica que podem motivar professores e técnicos, entusiasmando e transformando o ambiente escolar pelos trabalhos em grupo, pelo estímulo à criatividade, pela possibilidade de convivência mais atenta entre professores e alunos, pelo incentivo à avaliação permanente, pelo estímulo ao estudo aprofundado por parte dos educadores envolvidos no processo e pela oportunidade de introduzir, no trabalho escolar, a arte, a espiritualidade, a alegria e o desafio permanente para a busca de soluções inovadoras [sic]. (AMAZONAS, 2011, p. 77).
}

Apesar da dificuldade de entendimento do discurso presente nesse trecho do Projeto, que nos soa como algo incompleto, podemos depreender que é no Ensino Fundamental e Ensino Médio, que pode ser efetivado um ensino de qualidade a partir de uma nova ação pedagógica.

Para isso, o projeto propôs, mesmo que na retórica, um currículo cujo processo pedagógico deveria ser dinâmico e interativo, de modo a favorecer novas relações geradoras de saberes, entendendo professor e aluno como sujeitos da produção e reprodução do conhecimento. 
por isso, propõe-se um currículo baseado no domínio de competências básicas e não no acúmulo de informações. E ainda, um currículo que tenha vinculos com os diversos de vida dos alunos. (AMAZONAS, 2011, p. 27, grifo nosso).

Mesmo que no discurso do Projeto esteja explícita a importância da formação crítica do estudante, todavia, ao propor o domínio de "competências básicas" do sujeito, identificamos um currículo unilateral e, consequentemente, uma formação unilateral. A formação unilateral, de acordo com Manacorda (2007), forma um estudante sem conhecimento total de sua realidade, sem capacidade crítica para perceber-se como objeto da sociedade capitalista; torna-se, tão somente, um receptor de informações.

Cavaliere (2014, p. 1211) argumenta que "há um senso comum em torno da premissa de que mais tempo diário na escola trará resultados escolares melhores, embora ainda não existam pesquisas conclusivas no Brasil que os relacionem." A ampliação da jornada escolar, se, desconexa do Projeto Político Pedagógico escolar, e apenas ancorada na ideia de complementação do tempo, é insuficiente para a garantia da permanência e sucesso do estudante no ambiente escolar, pois muitos não atendem às expectativas do público-alvo, principalmente os estudantes e suas famílias.

Para dar conta desse objetivo, inicialmente, as escolas precisam se munir de infraestrutura adequada, pessoal e física, com a inserção de, além de professores em quantidade suficiente e formação adequada, outros profissionais que possam colaborar na formação desses alunos, haja vista as muitas atividades a que a escola é chamada a gestar.

Cavaliere (2002, p. 248) afirma que "A escola fundamental vem sendo instada, nos últimos anos, a assumir responsabilidades e compromissos educacionais bem mais amplos do que a tradição da escola pública brasileira sempre o fez." Isso ocorre diante da universalização da Educação Básica como estratégia para superação das desigualdades sociais implementadas no Brasil por meio das reformas efetivadas na década de 1990.

Essa ampliação das funções da escola, ao mesmo tempo em que possibilitou o maior acesso das classes populares à educação formal, desencadeou um processo de múltiplas funções à instituição, consequentemente, aumentou a dificuldade da instituição escolar em manter seu alunado no processo educacional. Cavaliere (2002, p. 249) afirma que:

Aos profissionais da escola foi incorporado um conjunto de responsabilidades educacionais, não tipicamente escolares, mas, sem o qual, o trabalho especificamente voltado para a instrução escolar torna-se inviável. São atividades relacionadas à higiene, saúde, alimentação, cuidados e hábitos primários. 
Com isso, a escola, precisou ser reinventada para atender, principalmente, as novas demandas e enfrentar as muitas dificuldades para manter e possibilitar o sucesso educacional do estudante.

Ganzeli (2011, p. 19) afirma que "a organização da escola na sociedade capitalista privilegia a separação entre o pensar e o agir, entre a concepção e a execução." Contudo, é possível que a escola pública, mesmo numa sociedade capitalista, marcada pelas contradições sociais, possa ser reinventada superando as formas autoritárias e alienantes presentes em seu cotidiano, marcas de um gerencialismo implementado na educação.

0 Projeto em questão seguiu os preceitos das reformas educacionais dos anos de 1990, que tinham como parâmetro as diretrizes das agências multilaterais. ${ }^{7}$ De acordo com Colares (2015, p. 249), deu-se destaque à "educação como um componente estratégico para o crescimento econômico entre os países, a redução da pobreza, a inclusão social e equidade", a partir de uma lógica de mercado, que impunha à educação o objetivo de formar o educando para a empregabilidade, concebendo a qualidade total da educação a partir de uma formação flexível e unilateral.

Vale ressaltar que a proposta da efetivação de um ensino de qualidade total, presente no Projeto, surgiu na década de 1990, e o estado do Amazonas vem intensificando a qualidade total na educação. Ferreira (2012, p. 62) afirma que

\begin{abstract}
A qualidade total nas politicas da rede estadual de ensino reapareceu com mais força tanto na reestruturação da educação básica, quanto em todo o processo de gestão escolar, visto que a retomada desse princípio regulador tem transformado as escolas de tempo integral num espaço de controle produtivista, no qual a certificação ISO 9.001/2008 é condição eminente de qualidade para a Seduc, conforme as políticas implementadas em $2009 \mathrm{em}$ Manaus. (FERREIRA, 2012).
\end{abstract}

Foi, portanto, na direção da qualidade total que foi construído o Projeto de Educação em Tempo Integral; uma herança da ideologia neoliberal efetivada nas políticas públicas estaduais no Amazonas, incorporando em seu currículo as diretrizes apontadas pela Organização das Nações Unidas para a Educação, a Ciência e a Cultura (UNESCO) para a educação para o século XXI: aprender a conhecer; aprender a fazer; aprender a viver; aprender a ser, conforme consta no referido Projeto:

Essas agências foram principalmente o Banco Mundial, Organização das Nações Unidas para Educação, Ciência e Cultura (Unesco) e a Comissão Econômica para América Latina e Caribe (Cepal). 
São incorporadas pelo Ensino Fundamental e o Ensino Médio com diretrizes gerais e orientadoras da proposta curricular, as quatro premissas apontadas pela UNESCO, como eixos estruturais da educação na sociedade contemporânea: aprender a conhecer (descobrir os caminhos dos conhecimentos, conhecer onde e como ele se organizal, aprender a fazer (vincular a educação escolar ao trabalho e às práticas sociais), aprender a viver (trabalhar a aprendizagem da convivência pois todos dependemos uns dos outros) e aprender a ser (capacidade de autonomia, julgamento e responsabilidade consigo e com o outro). (AMAZONAS, 2011, p. 22-23, grifo nosso).

Essas diretrizes foram estabelecidas pela Comissão Internacional de Educação para o século XXI, presidida por Jacques Delors em 1993. A comissão sustentou-se na premissa de que a educação seria a alternativa para a redução ou desaparecimento da desigualdade social nos países em desenvolvimento: “Ante os múltiplos desafios do futuro, a educação surge como um trunfo indispensável à humanidade na sua construção dos ideais da paz, da liberdade e da justiça social." (DELORS, 2000, p. 11). Para a Comissão, o sistema escolar como estava organizado era insuficiente para responder aos anseios da sociedade $e$ propôs a transformação gradativa desse sistema, acreditando na educação, especificamente na Educação Básica como um "passaporte para a vida”.

Duarte (2001) argumenta que o lema "aprender a aprender" foi utilizado com muita frequência no campo educacional como posição pedagógica inovadora e progressista. 0 autor afirma que o lema se apresenta com uma função ideológica para manutenção da hegemonia burguesa no campo educacional.

“É interpretado como uma expressão inequívoca das proposições educacionais afinadas com o projeto neoliberal, considerado projeto político de adequação das estruturas e instituições sociais às características do processo de reprodução do capital no final do século XX." (DUARTE, 2001, p. 3).

É nesse sentido que o lema "aprender a aprender" legitima a ideologia neoliberal no contexto educacional ou, ainda, por meio de um discurso pós-moderno, cujo projeto de transformação política consciente foi operacionalizado por meio de propostas autoritárias e verticalizadas.

No Projeto em questão, o lema "aprender a aprender" foi apresentado como palavra de ordem caracterizando uma educação democrática na rede pública de educação do estado do Amazonas.

Entendemos que o lema "aprender a aprender" atende principalmente às necessidades econômicas, pois, de acordo com Duarte (2001), nenhum ser humano precisa "aprender a aprender", uma vez que ele já nasce com essa capacidade. 0 que o estudante precisa é receber orientações e subsidios que the permitam desenvolver suas capacidades formativas. 


\section{CONSIDERAÇÕES FINAIS}

Ao analisarmos o Projeto em questão, por vezes percebemos um discurso que caminhava na direção da efetivação de uma educação de qualidade socialmente referenciada, capaz de contribuir com a formação integral dos estudantes em todas suas dimensões formativas.

A partir do estudo realizado, tendo em vista o objetivo deste artigo, qual seja: demonstrar em que consiste o padrão de qualidade no Projeto de Educação em Tempo Integral, em voga, na rede estadual do Amazonas, aferimos que o padrão de qualidade no Projeto de Educação em Tempo Integral, está fundamentado numa concepção mercadológica a partir de preceitos neoliberais, especificamente pela adoção do lema aprender a aprender e tudo o que está imbuído nesse conceito.

0 lema "aprender a aprender", na concepção de Saviani (2014), foi apresentado como uma ideia de liberdade de aprendizagem para o aluno, no entanto, significa um "slogan para a ignorância", pois o aprendiz não é livre e só pode ser assim considerado, após dominar o objeto de aprendizagem, mas quando isso acontece ele já deixou de ser aprendiz.

Para superação dessa ideologia neoliberal presente na educação por meio do slogan "aprender a aprender", faz-se necessário a efetivação de uma teoria pedagógica que seja compatível com o compromisso político de superação das contradições sociais que perpassam por toda a sociedade capitalista e se fazem presentes no contexto educacional. Uma pedagogia que transcenda ao sistema tradicional e alienante da educação para uma concepção pedagógica que compreenda o estudante como sujeito histórico, capaz de perceber-se numa sociedade dividida em classes sociais, buscando essa superação.

Na concepção de Saviani (2018), a partir da Pedagogia histórico-crítica, articulada aos interesses das classes populares é que a escola buscará métodos mais eficazes, favorecendo o diálogo entre os sujeitos do processo educacional, objetivando a troca de conhecimentos acumulados historicamente.

A possibilidade da efetivação do direito à educação, com qualidade, será efetiva quando a escola considerar os vários momentos que fazem parte da vida dos estudantes, tais como: o interesse, o tempo, o ritmo de aprendizagem, mas sem desconsiderar os conhecimentos sistematicamente acumulados, como perpetuação dos saberes construídos.

Concordamos com Cavaliere (2007), que uma escola em tempo integral que pretenda a formação do jovem para atuação numa sociedade marcada pela complexidade das relações sociais e que visa à efetivação de uma sociedade democrática, não pode 
concentrar suas ações pedagógicas em conteúdos estanques, verticalizados e unilaterais, mas propiciar meios para uma formação omnilateral do sujeito em suas múltiplas capacidades de aprendizagem com vistas à transformação social. Há, neste sentido, a necessidade de diversificação e aprofundamentos de experiências compartilhadas, tanto para alunos, como para os profissionais da educação.

A Educação em Tempo Integral deve ser entendida como um direito universal e não como um dispositivo de exclusão de muitos em detrimento de poucos. Não pode se configurar como uma educação compensatória para os mais necessitados economicamente, mas prevalecer a igualdade de oportunidades a todos os estudantes.

As escolas de tempo integral, além da instrução escolar, deveriam ser as construtoras do saber, da justiça social, promovendo a formação integral do sujeito nos aspectos intelectual, físico, ético, moral e políticos. Deveriam possibilitar a construção da cidadania, na difusão cultural de crianças e na formação para o trabalho dos adolescentes a partir da efetivação de uma educação de qualidade socialmente referenciada.

\section{REFERÊNCIAS}

ALVES-MAZZOTTI, A. J.; GEWANDSZNAJDER, F. 0 método nas ciências naturais e sociais pesquisa quantitativa e qualitativa. 2: ed. São Paulo: Thompson, 2002.

AMAZONAS. Constituição Política do Estado do Amazonas. Diário Oficial do Estado

n²6.824, 5 out. 1989. Disponivel em: http://www.ale.am.gov.br/. Acesso em: 6 fev. 2017.

AMAZONAS. Educação em Tempo Integral. Amazonas: SEDUC, 2008a.

AMAZONAS. Padeam. Amazonas: SEDUC, 2012. Disponível em: http://www.educacao.am.gov.br/padeam-2/. Acesso em: 30 jul. 2018.

AMAZONAS. Plano Estadual de Educação do Amazonas - PEE/AM: uma construção da sociedade amazonense. Manaus: [s. n.], abr. 2008b. Disponível em: http://diario.imprensaoficial.am.gov.br/diariooficial. Acesso em: 20 jan. 2018.

AMAZONAS. Plano Estadual de Educação do Amazonas - PEE-AM 2015-2025. Manaus: [s. n.], 2015. Disponivel em: http://diario.imprensaoficial.am.gov.br/diariooficial/. Acesso em: 20 jan. 2008.

AMAZONAS. Proposta pedagógica das escolas da rede estadual de ensino de educação em tempo integral. Amazonas: SEDUC, 2011.

BANCO MUNDIAL. Prioridades y estrategias para la educación. Examen del Banco Mundial. Washington, DF: Banco Mundial, 1995. Disponivel em: http://documents.worldbank.org/curated/ pt/715681468329483128/pdf/14948010spanish.pdf . Acesso em: 8 jan. 2019. 
BRASIL. Constituição. República Federativa do Brasil de 1988. Brasilia, DF: Senado Federal, 5 out. 1988. Disponivel em: http://www2.camara.leg.br/atividade.legislativa/legislacao/Constituicoes_Brasileiras/ constituicao1988.html/constituicao-da-republica-federativa-do-brasil_texto-atualizado. Acesso em: 15 jan. 2018.

BRASIL. Lei n. 9.394, de 20 de dezembro de 1996. Estabelece as diretrizes e bases da educação nacional. Diário Oficial da União, Brasília, DF, 23 dez. 1996. Disponivel em: http://www2.camara.leg.br/ legin/fed/lei/1996/lei-9394-20-dezembro-1996-362578-norma-pl.html. Acesso em: 12 jan. 2018.

BRASIL. Lei n. 13.005, de 25 de junho de 2014. Aprova o Plano Nacional de Educação - PNE e dá outras providências. Diário Oficial da União, Brasília, DF, 26 jun. 2014. Disponível em: http://www.planalto.gov. br/ccivil_03/_ato2011-2014/2014/lei/113005.htm. Acesso em: 14 jun. 2018.

BRASIL. Ministério da Educação. Programa mais educação: passo a passo. Brasilia, DF, 2007. Disponível em: http://portal.mec.gov.br/dmdocuments/passoapasso_maiseducacao.pdf. Acesso em: 28 maio. 2018

CARDOSO, F. H. Reforma do Estado. In: CARDOSO, F. H. Reforma do Estado e administração pública gerencial. 3. ed. Rio de Janeiro, RJ: FGV, 1999.

CARDOSO, I. M. R. Programa escola integral no Amazonas: um estudo sobre a organização do tempo em uma escola de Manaus. 2016. Dissertação (Mestrado em Educação) - Universidade Federal de Juiz de Fora, Juiz de Fora, 2016. Disponivel em: https://repositorio.ufjf.br/jspui/handle/ufjf/3113. Acesso em: 14 ago. 2018.

CAVALIERE, A. M. Anísio Teixeira e a educação integral. Paidéia, v. 20, n. 46, 2010. Disponivel em: http:// www.scielo.br/scielo.php?script=sci_arttext\&pid=S0103-863X2010000200012\&lng=pt\&tlng=pt. Acesso em: 20 mar. 2018.

CAVALIERE, A. M.; COELHO, L. M. C. da C. Para onde caminham os Cieps? Uma análise após 15 anos. Cadernos de Pesquisa, n. 119, p. 147-174, 2003. Disponível em: http://www.scielo.br/scielo.php?script=sci_ arttext\&pid=S0100-15742003000200008\&lng=pt\&tlng=pt. Acesso em: 20 set. 2018.

CAVALIERE, A. M. Educação integral: uma nova identidade para a escola brasileira? Educação \& Sociedade, v. 23, n. 81, p. 247-270, 2002. Disponivel em http://www.scielo.br/scielo.php?script=sci_ arttext\&pid=S0101-73302002008100013\&lng=pt\&tlng=pt. Acesso em: 20 set. 2018.

CAVALIERE, A. M. Escola pública de tempo integral no Brasil: filantropia ou política de Estado? Educação \& Sociedade, v. 35, n. 129, p. 1205-1222, 2014. Disponivel em: http://www.scielo.br/scielo. php?script=sci_arttext\&pid=S0101-73302014000401205\&lng=pt\&tlng=pt. Acesso em: 20 ago. 2018.

CAVALIERE, A. M. Escolas de tempo integral versus alunos em tempo integral. Educação integral e tempo integral, v. 22, n. 80, p. 51-63, 2009. Disponivel em: http://emaberto.inep.gov.br/index.php/emaberto/article/view/2220 Acesso em: 20 ago. 2018. 
CAVALIERE, A. M. Tempo de escola e qualidade na educação pública. Educação e sociedade, Campinas, v. 28 , n. 100, p. 1015-1035, 2007. Disponivel em: http://www.scielo.br/scielo.php?script=sci_ arttext\&pid=S0101-73302007000300018\&lng=pt\&tlng=pt. Acesso em: 20 set. 2018.

COELHO, L. M. C. da C.; MAURICIO, L. V. Sobre Tempo e Conhecimentos Praticados na Escola de Tempo Integral. Educ. Real., v. 41, n. 4, p. 1095-1112, 2016. D0l: https://doi.org/10.1590/2175-623660673.

COLARES, A. A.; SOUZA, R. Educação e diversidade: interfaces e desafios na escola de tempo integral. Revista HISTEDBR On-line, n. 66, p. 247-266, dez. 2015. Disponivel em: https://periodicos.sbu.unicamp. br/ojs/index.php/histedbr/issue/view/1028. Acesso em: 12 nov. 2018.

CONSELHO ESTADUAL DE EDUCAÇÃO DO AMAZONAS. Resolução n. 17/2011 - CEE/AM. Amazonas: CEE, 2011. Disponivel em: http://www.cee.am.gov.br/. Acesso em: 20 abr. 2017.

CONSELHO ESTADUAL DE EDUCAÇÃO DO AMAZONAS. Resolução n. 112/2008-CEE/AM. Amazonas: CEE, 2008. Disponivel em: http://www.cee.am.gov.br/. Acesso em: 20 abr. 2017.

DELORS, J. Educação: um tesouro a descobrir: relatório para a Unesco da Comissão Internacional sobre Educação para o século XXI. São Paulo, SP: Cortez, 2000.

DOURADO, L. F.; OLIVEIRA, J. F. de; SANTOS, C. de A. A qualidade da educação: conceitos e definições. Brasilia, DF: Instituto Nacional de Estudos e Pesquisas Educacionais Anísio Teixeira, 2007. Disponível em: http://portal.inep.gov.br/documents/186968/485287/A+qualidade+da+educa\%C3\%A7\%C3\%A3o+con ceitos ${ }^{+} e^{+}$defini\%C3\%A7\%C3\%B5es/8926ad76-ce32-4328-8a26-5139ccedddb42version=1.3. Acesso em: 15 mar. 2019.

DUARTE, C. S. Direito público subjetivo e políticas educacionais. São Paulo em Perspectiva, v. 18, n. 2, p. 113-118, 2004. Disponivel em: http://www.scielo.br/scielo.php?script=sci_arttext\&pid=S0101$-73302007000300004 \&$ lng=pt\&tlng=pt. Acesso em: 20 ago. 2018.

DUARTE, N. As pedagogias do aprender a aprender. E algumas ilusões da assim chamada sociedade do conhecimento. Revista Brasileira de Educação, n. 18, p. 35-40, set./dez. 2001. Disponível em: http:// www.scielo.br/pdf/rbedu/n18/n18a04.pdf. Acesso em: 4 jul. 2019.

FERREIRA, J. N. 0 Ensino Médio nas escolas de tempo integral. 2012. Dissertação (Mestrado em Educação) - Universidade Federal do Amazonas, Manaus, 2012. Disponível em: https://tede.ufam.edu.br// handle/tede/3180. Acesso em: 6 dez. 2018.

GANZELI, P. 0 político, o pedagógico e a pesquisa. In: GANZELI, P. Reinventando a escola pública por nós mesmos. Campinas, SP: Editora Alínea, 2011.

MACIEL, A. C. et al. Percursos da Educação Integral em Manaus: gestão currículo e metodologia. In: MACIEL, A. C. et al. Currículo e metodologia da educação integral politécnica: aportes ao trabalho pedagógico coletivo. Porto Velho, RO: Temática Editora, 2016. 
MACIEL, A. C. et al. Perfil da Educação Integral em Manaus: elementos para a coleta de dados educacionais a partir do Boto-BDE. In: MACIEL, A. C. et al. Gestão da educação integral politécnica: uma proposta para o Brasil. Porto Velho, RO: EDUFRO, 2013. v. 2.

MANACORDA, M. A. Marx e a pedagogia moderna. Campinas, SP: Editora Alínea, 2007.

MENEZES, S. B. Modelos de gestão escolar no Estado do Amazonas: entre o dito e o feito. 2009. Dissertação (Mestrado em Educação) - Universidade Federal do Amazonas, Manaus, 2009. Disponível em: https://tede.ufam.edu.br/bitstream/tede/3214/1/Dissertacao\%20Samara\%20Barbosa\%20de\%20 Menezes.pdf. Acesso em: 15 maio 2020.

PARO, V. H. Diretor escolar: educador ou gerente? São Paulo: Cortez, 2015.

SAVIANI, D. Aprender a aprender: um slogan para a ignorância. Livre Pensamento, 26 ago. 2014. Disponivel em: https://livrepensamento.com/2014/08/26/aprender-a-aprender-um-slogan-para-a-ignorancia/. Acesso em: 14 ago. 2018.

SAVIANI, D. Escola e Democracia. 43. ed. rev. ed. Campinas, SP: Autores Associados, 2018.

SILVA, C. A. 0 sistema público de educação de tempo integral em Manaus e as possibilidades da educação integral politécnica. 2017. Dissertação (Mestrado em Educação) -Universidade Federal de Rondônia, Porto Velho, 2017. Disponivel em: http://www.ppge.unir.br/uploads/62248421/arquivos/ DISSERTA_____CINTIA_AD_LIA_DA_SILVA_531361974.pdf. Acesso em: 16 jul. 2018.

UNICEF. Percursos da Educação Integral: em busca da qualidade e da equidade. 1. ed. São Paulo: CENPEC: Fundação Itaú Social, 2013. Disponivel em: https://www.maxwell.vrac.puc-rio.br/Busca_etds. php?strSecao=resultado\&nrSeq=16599@1. Acesso em: 18 jun. 2018.

Endereço para correspondência: Rua 29 de agosto, 186, Centro, 69800-000, Humaitá, Amazonas, Brasil; angela.biase@hotmail.com 